\title{
Data Communication in Internet of Things: Vision, Challenges and Future Direction
}

\author{
Jammel Mona \\ University of Kufa Iraq, Najaf, Iraq \\ *Corresponding author, e-mail: jammelm.mana@uokufa.edu.iq
}

\begin{abstract}
Ubiquitous technologies based heterogeneous networks has opened a new paradigm of technologies, which are enabled with various different objects called Internet of things (loT). This field opens new door for innovative and advance patterns with considerable potential advantages in the shape of plethora of monitoring and infotainment applications around us. Data communication is one of the significant area of research in loT due to its diverse network topologies, where diverse gadgets and devices have integrated and connected with each other. In order to communicate among devices and users, routing should be relible, secure and efficient. Due to diverse and hetrogenous netwok environment, the most of the existing routing solutions do not provide all quality of services requirement in the network. In this paper, we discuss the existing routing trend in IoT, vision and current challenges. This paper also elaborates the technologies and domains to drive this field for future perspectives. The paper concludes with discussion and main points for new researchers in terms of routing to understand about current situation in loT.
\end{abstract}

Keywords: WSN, IoT, routing, devices, applications, 4G, automation

Copyright $(2018$ Universitas Ahmad Dahlan. All rights reserved.

\section{Introduction}

Internet of Things (IOT) is the arrangement of network systems with physical objects or "things" integrated with sensor nodes for data communication and provide different critical and infotainment services in networks. In loT, the devices are controlled remotely and provide integration among computer systems and physical world. The applications promote the communication services and enhance, effective and precise advantages for users [1]. Technologies enabled devices have extraordinarily characteristics through its embedded computing system capabilities to operate inside and outside the existing internet infrastructure [2,3]. The loT applications are practically boundless and available anywhere and open new development, learning and advance features opportunities. The applications are working for different purposes such as construction, home automation, heath care, transportation, agriculture, and wearables.

The connectivity between devices is established through wireless technologies including WiFi, cellular, WiMAX and $4 G$ technologies [4]. For home automation, the loT applications have gained popularity due to its acceptable security, affiliated accessories to abbreviation activities, which offer advance intelligent solutions [5]. In addition, the loT also offers the applications for smart cities where applications reduce burning incidents, offer acute lighting, surveillance cameras, cartage control, centralized and chip arrangement ascendancy. IoT is abstraction technology for healthcare sector where the services provide patient surveillance, drugs tracking, ambulance telemetry. Wearable technology is another absolute application area that covers entertainment, fitness, navigation and tracking services.

The loT has abstruse implications for automated internet enable things. With acute metering, machine-to-machine communications, temperature monitoring, calm air superior and acceptable automation will become added abreast. In this fast-growing world from last few year things have been changing drastically that no can imagine. Recently, technologies reached to the extant, where automation is a key for everything. loT is technology in which everything is connected to each other to facilitate people in every aspect [4]. Emergence of loT will totally change our way of living from homes to industry with lot of benefits. 
As shown in the Figure 1 the connected homes, mobile devices, automotive, healthcare, industry, when all these things come under single platform of loT. Users don't have to make decision on their own, machine become more efficient to help the users for different decisions. Different types of algorithms have been used to collect large amount of data from different devices and make them effective and useful for decision making. Lot of research is undergoing in this field to make it more convenient to connected with heterogeneous devices. Therefore, different communication protocols, architecture, security and privacy protocols are required to make these networks more effective [6]. IoT can benefit us in smarts homes in the form of smart metering, smart energy, security, in automotive by improving vehicular fault detection, in healthcare by instant patient health report, in industry by quantity and qualitative check.

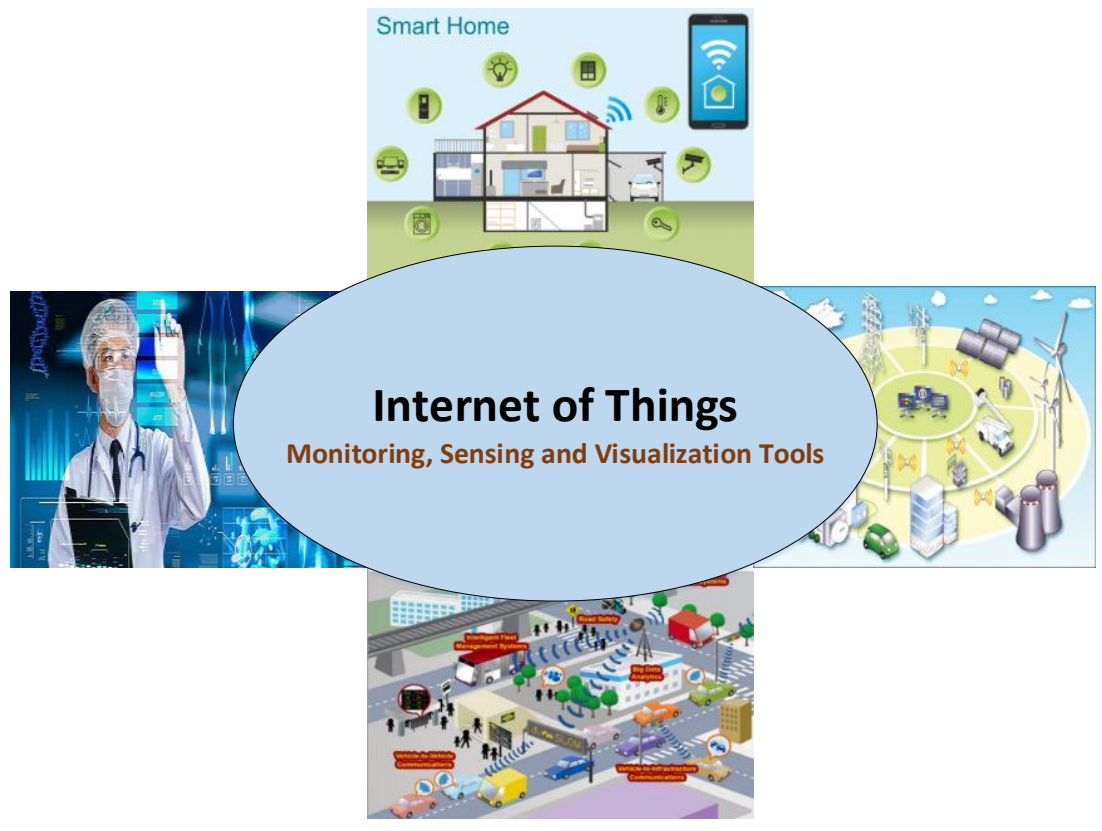

Figure 1. loT services

In this paper, we discuss the trend of IoT, its data communication requirements and methods. In addition, paper also presents the loT vision, existing challenges and future direction. The remaining paper is organized as follows: Section 2 presents the data communication processes and existing protocol. Section 3 discusses the data routing challenges. Section 4 discusses the future direction and then paper will conclude in last section.

\section{Data Communication}

Information and Communication technologies have depended on reliable data routing and communication processes. Data communication is one of the significant part for every technology where the nodes send data in the network or to the destination and facilitates the network by sending the data towards the destination. Some applications are based on real-time data communication and some are based on normal data communications. Routing refers to selected and feasible path towards destination for data sending in the network. Some protocols establish routing table to keep the neighbor node record and route the data accordingly.

Distance vector and link state routing is one of the example to find the shortest route in the network [7]. However, the ad hoc networks have changed the way of routing where most of the wired network based routing protocols are not working well because these networks are working without any preexisting infrastructure. The sensor nodes have limited processing and battery and far behind with traditional computers capabilities. Therefore, there is need to design more advance and intelligent routing protocols for work in loT and ad hoc wireless domain. First 
we discuss the traditional protocols in detail and then discuss the advance protocols used for loT.

\subsection{Routing Protocols}

This section discusses the routing trend in loT and highlights the in-depth functionalities and processes. First, we discuss that why the traditional AODV (Ad hoc on Demand Distance Vector) [8], TORA (Temporally Ordered Routing Algorithm) [9], and SDR (Dynamic Source Routing) [10], protocols have suffered in loT. The new protocols designed for loT are 6LoWPAN (IPv6 over 802.15.4) [11], RPL (IPv6 Routing protocols for Low Power \& Lossy Network) [12] and CoAP (Constrained Application Protocol) [13].

AODV protocol is a reactive protocol designed by the Internet Engineering Task Force (IETF) group in 2003. It uses Route Request (RREQ) and Route Reply (RREP) cycle whenever a packet sends to unknown destination. During this period, a route finds and keep record hopby-hop, where every single node individually aware about direct neighbor towards the distinct destination. Whenever a link breakdown, protocol is often communicated by downstream within the same way. As a result, the routes are individually keep if necessary. This protocol manages routing table and update the table through discovery messages dynamically. If any node broadcast the message in network and still not in neighbor node routing table, then a route request message is broadcast and record will update in routing table. The update entry is useful for reverse path in future. The entries in routing table has limited time and usually the timer is set in time frame where request can broadcast and route reply information come back in entire network. For reversers path, protocol waits to complete the reply packet process and each node keep record of previous forwarding and establish a reverse path where the data will move later on.

However, in this process the assumption is that all links are symmetric nature without any unidirectional links. Due to this assumption, protocol utilize same path to forward reply packet. In addition, protocol also uses sequence number for stale and fresh routes. Periodic short messages have used to establish connectivity among sensor nodes and also helpful for link failure information. This strategy increases the number of nodes and has multiple routes between source and destination for route discovery. Whenever, a link fails then user adopted load balancing method.

Due to AODV least structure, it is simple and due to its hope count strategy as a metric and feasible for energy saving. Various extension have designed after this protocols with minor changings and improvements including AODVv2 which has adopted by the Mobile Ad hoc Networks (MANET) [14].

TORA is another well-known protocol to handle topological changing of network. A key concept behind this protocol is decoupling messages broadcasting to control topological changing rate. This protocol is creating, maintaining, and erasing the routes and model the network as graph. In graph, all the edged of graph are undirected and link with network, where each link directed or undirected with node $i$ and $j$ respectively. Every node maintains height metric which is utilize for directions to link with neighbor nodes. The nature of created route is reactive or proactive. Reactive method is used to create series of directed links using construction of directed acyclic graph root by query and reply process. Whenever, source node sends query messages to neighbor nodes to establish a route for data routing in the network. The query messages are broadcasted until establish the route towards the destination. Whenever, route will stablish an update message send to all neighbor nodes. On the other hand, in the proactive mode' destination node route creation by sending optimization packet and further process by forwarder and neighbor node.

The SDR protocol adopts strategy in which this protocol determines complete path from which data travel in the network. This protocol adds the path in packet header and each node maintains rote cache and route information and route discovery message is used to find new route. This protocol is dynamic in nature and whenever the source node wants to send the data first it checks its cache. If the entry of required destination exists, then directly send the data to destination otherwise again route finding process will start using route request packet. The route request packet has route record where sequence of next hop information exists with unique ID. Whenever, neighbor receive the route request messages and if any neighbor node has entry in its cache then it sends route reply otherwise again broadcast route request. 
After route establishment in this protocol, a route reply routed reverse based on recorder path and sometime node uses information from its own cache. One of the enhanced function in this protocol is that where nodes adopted exponential back off method and forward route back reply. The nodes also have promiscuous mode from which node learn from previous route request messages. However, this promiscuous listening has some drawbacks like processing overhead which leads to more packets in the network.

This protocol is not taking periodic updates into account and still has network overhead. This is because of embeds the entire route information in every packet. In addition, the protocol overhead increases with mobility of users in loT networks and in the presence of busty traffic in the network. For low power networks, another standard 6LoWPAN to enable the IPv6 packets was designed especially for IEEE 802.15.4. In this method, the main idea is that where internet protocol has applied for small and less capabilities devices like in loT networks. The main objective of this protocol to adopt "IP over Foo" to address the needs of IPv6, such as enhance the address size by 1280 bytes. The concept of IPV6 has adopted to make a set of headers which allow for efficient encoding for large size addresses and then compressed into small header. In some cases, the compressed size is up to 4 bytes. Protocol also supports the mesh networks, segmentation and reassemble methods. This protocol has worked with some assumptions such as how the "stacked header" idea will apply and feasible for users.

Another effort is Routing Protocol for Low Power (RPL) IPv6 was designed for loT networks. In this type, the low power devices like in loT are using for data communication. However, the data rate is low in this protocol and data transmission is not reliable and has more data loss rate. This protocol uses point-to-point and multipoint traffic. This protocol is working with sink node and utilize energy resources and computation capabilities of sink node. It builds a DODAG (Destination Oriented Acyclic Graph) which has a root to directing the traffic towards the sink node in the network. This graph has information object and identity and rank information. Because the destination information object is broadcasting proactively for explore network topology.

Table 1. IoT Applications

\begin{tabular}{|c|c|c|c|c|}
\hline IoT Areas & Technologies & Network Size & Energy & Devices \\
\hline $\begin{array}{c}\text { Smart Agriculture } \\
{[15]}\end{array}$ & $\begin{array}{l}\text { Satellite Communication, } \\
\mathrm{WiFi}\end{array}$ & Medium/Large & Harvesting & $\begin{array}{l}\text { Local and shared } \\
\text { server, WSN }\end{array}$ \\
\hline Smart City [16] & LTE, 3 and $4 \mathrm{G}$ & Medium/Large & $\begin{array}{c}\text { Rechargeable batteries, } \\
\text { harvesting }\end{array}$ & WSN, RFID \\
\hline $\begin{array}{c}\text { Smart Water } \\
\text { Management [17] }\end{array}$ & Microwave links, WiFi & Large & Harvesting & Single sensor \\
\hline $\begin{array}{l}\text { Smart } \\
\text { Transportation [18] }\end{array}$ & $\begin{array}{c}\text { WiFi, Satellite } \\
\text { Communication, WiMAX }\end{array}$ & Large & $\begin{array}{c}\text { Rechargeable batteries, } \\
\text { harvesting }\end{array}$ & $\begin{array}{l}\text { WSN, Single } \\
\text { sensors }\end{array}$ \\
\hline Smart Retail [19] & LTE, 3 and $4 \mathrm{G}$, Backbone & Small, & Rechargeable batteries & Smart retail \\
\hline Smart Home [20] & WiFi, 3 and $4 \mathrm{G}$ & Small & Rechargeable batteries & WSN, RFID \\
\hline
\end{tabular}

\section{Key Routing Challenges in loT}

For finding the shortest route in wired network, usually link state and distance routing are needed. These types of protocol are not feasible for ad hoc networks due to its limited bandwidth and infrastructure less nature [21]. Therefore, still loT network have suffered with routing issues and need to design new diverse protocols to handle loT networks. Some of the existing routing challenges are as follows:

\subsection{Traffic Patterns}

The existing routing protocols adopted for IOT have not designed to follow the area patters for sensor deployments. Since patterns vary from network to network, the existing protocols have not fulfilled the exiting need of network and not feasible for all networks. For every subdivision, there is need for one protocol in loT [22].

\subsection{Energy Efficiency}

The deployment of sensor nodes and extend the battery life of sensor nodes is one of the requirement of loT networks. A routing protocol processes has important role to drain the sensor nodes energy and more complex protocols consume more energy and sensor nodes 
depleted in network and disturb the network. An intelligent protocol should be resourceful in terms of energy consumption for loT-based network.

\subsection{Scalability}

The new protocols have to more scalable to adjust with loT network size where around hundreds to thousands nodes are working with each other. Scalability is one of the requirement for heterogeneous networks where different types of standards and protocols have working in the network.

\subsection{Mobility}

The loT networks are static or dynamic where sensor nodes are moving with different patterns in the network. Even though the loT does not typically has high mobility and need for an intelligent protocol to handle sparse and dense areas in loT. In addition, to fulfill the loT network requirements, different unique challenges make these networks more critical and difficult.

\subsection{Bi-Directionality}

Because of heterogeneous network technologies, loT has bidirectional connectivity in the network. Therefore, the links have not any guarantee to establish route. An intelligent protocol needed to handle bi directionality links and divert these links into one direction methods.

\subsection{Transmitter usage}

Transmitter has a significant component for data transmission in every network. In addition, remitter also has positive and negative impact on energy consumption. So, the question in term of loT is that how to design an efficient transmitter to work with loT devices and avoid networks from any sort of noise and interference.

\section{Conclusion}

Various different types of routing protocols have been designed for loT. The protocols offer the appropriate and possible routing criteria to match the loT data communication and network requirements. While none of the protocols may fits in all-solutions, because of heterogeneous nature of loT networks. In addition, due to new filed' various existing protocols have not tested in loT. This is the reason; still network has suffered with various routing challenges such as scalability, diverse traffic patterns, dynamic topologies, mobility and diversity. In addition, the attributes and topologies of loT make these networks more complicated. These all factors lead to design new and smart protocols which are publically accessible and fit for future demands. This paper provides an overview in the field of loT to study the network challenges, applications, vision and future requirements.

\section{References}

[1] J Gubbi, R Buyya, S Marusic, M Palaniswami. Internet of Things (loT): A vision, architectural elements, and future directions. Future generation computer systems. 2013; 29: 1645-1660.

[2] SDT Kelly, NK Suryadevara, SC Mukhopadhyay. Towards the implementation of loT for environmental condition monitoring in homes. IEEE Sensors Journal. 2013; 13: 3846-3853.

[3] KN Qureshi, AH Abdullah, O Kaiwartya, F Ullah, S lqbal, A Altameem. Weighted link quality and forward progress coupled with modified RTS/CTS for beaconless packet forwarding protocol (B-PFP) in VANETs. Telecommunication Systems. 2016.

[4] I Lee, K Lee. The Internet of Things (IoT): Applications, investments, and challenges for enterprises. Business Horizons. 2015; 58: 431-440.

[5] KN Qureshi, AH Abdullah, A Mirza, RW Anwar. Geographical forwarding methods in vehicular ad hoc networks. International Journal of Electrical and Computer Engineering. 2015; 5.

[6] X Jia, Q Feng, T Fan, Q Lei. RFID technology and its applications in Internet of Things (IOT). Consumer Electronics, Communications and Networks (CECNet), 2012 2nd International Conference. 2012: 1282-1285.

[7] KN Qureshi, F Bashir, S lqbal, RW Anwar. Systematic study of geographical routing protocols and routing challenges for Vehicular Ad hoc Networks. Emerging Technologies (ICET), 2017 13th International Conference on. 2017: 1-6. 
[8] C Perkins, E Belding-Royer, S Das. Ad hoc on-demand distance vector (AODV) routing. 2070-1721. 2003.

[9] V Park. Temporally-ordered routing algorithm (TORA) version 1 functional specification. Draft-ietfmanet-tora-spec-03. Txt. 2000.

[10] J Jetcheva, D Johnson, D Maltz, Y Hu. Dynamic source routing (DSR). Internet Draft, draft-ietfmanet-dsr-06. Txt. 2001.

[11] G Mulligan. The 6LoWPAN architecture. Proceedings of the 4th workshop on Embedded networked sensors. 2007: 78-82.

[12] T Winter. RPL: IPv6 routing protocol for low-power and lossy networks. 2012.

[13] C Bormann, AP Castellani, Z Shelby. Coap: An application protocol for billions of tiny internet nodes. IEEE Internet Computing. 2012; 16: 62-67.

[14] T Kabir, N Nurain, MH Kabir. Pro-AODV (Proactive AODV): Simple modifications to AODV for proactively minimizing congestion in VANETs. Networking Systems and Security (NSysS), 2015 International Conference on. 2015: 1-6.

[15] S. o. M. a. E. Surveillance. 2011.

[16] JM Hernández-Muñoz, JB Vercher, L Muñoz, JA Galache, M Presser, LAH Gómez, et al. Smart cities at the forefront of the future internet. The Future Internet Assembly. 2011: 447-462.

[17] S Bainbridge, C Steinberg, M Furnas. GBROOS_an ocean observing system for the Great Barrier Reef. International Coral Reef Symposium. 2010: 529-533.

[18] M Zhang, T Yu, GF Zhai. Smart transport system based on "The Internet of Things". Applied mechanics and materials. 2011: 1073-1076.

[19] F. R. C. S.R.L. Labs, SAP Research Living Labs.

[20] CD Kidd, R Orr, GD Abowd, CG Atkeson, IA Essa, B Maclntyre, et al. The aware home: A living laboratory for ubiquitous computing research. International Workshop on Cooperative Buildings. 1999: 191-198.

[21] T Alam, M Aljohani. Design and implementation of an Ad Hoc Network among Android smart devices. Green Computing and Internet of Things (ICGCloT), 2015 International Conference on. IEEE. 2015.

[22] A Sharma, T Alam, D Srivastava. Ad Hoc Network Architecture Based on Mobile Ipv6 Development. Advances in Computer Vision and Information Technology. 2008: 224. 